\title{
Comparison of Glycemic Excursion in Patients with New Onset Type 2 Diabetes Mellitus before and after Treatment with Repaglinide
}

\author{
Sharabeh Hezarkhani ${ }^{1}$, Shokufeh Bonakdaran ${ }^{2}$, Reza Rajabian ${ }^{2}$, Najmeh Shahini ${ }^{3}$ and Abdoljalal \\ Marjani*,4 $^{*}$
}

${ }^{I}$ Department of Internal Medicine, Golestan University of Medical Sciences, Gorgan, Iran

${ }^{2}$ Department of Internal Medicine, Mashhad University of Medical Sciences, Mashhad, Iran

${ }^{3}$ Student Research Committee, Golestan University of Medical Sciences, Gorgan, Iran

${ }^{4}$ Department of Biochemistry and Biophysics, Metabolic Disorders Research Center, Gorgan Faculty of Medicine, Golestan University of Medical Sciences, Gorgan, Golestan Province, Iran

\begin{abstract}
Due to industrialization and sedentary life, incidence of type 2 diabetes (DM2) is increasing seriously. Repaglinide is a glucose reducing agent that predominantly reduces post-prandial glucose. Continuous glucose monitoring system (CGMS) monitors blood glucose excursions over a 3-day period. CGMS can be used as a therapeutic and diagnostic instrument in diabetics. There are not enough studies about using CGMS in DM2. The aim of this study was to determine the blood glucose excursions in patients with new onset of DM2. 10 patients with new onset of DM2 were entered to this study. As the first therapeutic management, patients received diabetic diet and moderate exercise for 3-weeks, if they did not achieve blood glucose goal (Fasting blood glucoser (FBG) $<120 \mathrm{mg} / \mathrm{dl}$, 2-hour postprandial blood glucose (2hpp) $<180 \mathrm{mg} / \mathrm{dl}$ ), were considered to undergo 3-days CGMS at baseline and after 4-weeks on Repaglinide (0.5mg three times before meals). Mean excursions of blood glucose were not different at the onset and at the end of treatment ( $6 \pm 4.05 \mathrm{VS}$ 7.6 \pm 5.2 episodes, $\mathrm{P}=0.49$ ). There were also no significant differences between mean duration of hypoglycemic episodes (zero VS 5.1 \pm 14.1 hours, $\mathrm{P}=0.28$ ) and hyperglycemic episodes before and after therapy $(7.6 \pm 5.2$ VS 5.7 $\pm 4.1, \mathrm{P}=0.42$ ), but mean hyperglycemia duration was significantly reduced at the end of therapy $(21 \pm 26.17$ VS $57.7 \pm 35.3, P=0.001)$. $P a-$ tients experienced a mean of $0.3 \pm 0.67$ episodes of hypoglycemia after therapy showed no significant difference before it $(\mathrm{P}=0.19)$. Mean FBG (with CGMS) was significantly lower after therapy than before it $(142.9 \pm 54.31 \mathrm{VS} 222.9 \pm 82.6, \mathrm{P}$ $<0.001)$.

This study showed the usefulness of CGMS not only as a diagnostic but also as an educational and therapeutic tool that in combination with Repaglinide (with the lowest effective dose and duration) can significantly reduce FBG and glycemic excursions in DM2 patients and hypoglycemic events are low.
\end{abstract}

Keywords: Repaglinide, Glycemic excursions, Type 2 diabetes, Continuous glucose monitoring system.

\section{INTRODUCTION}

Type 2 diabetes mellitus (DM2) increases with age, social industrialization and sedentary life style. Some studies have shown postprandial hyperglycemia and glycemic excursions in DM2 which are associated with cardiovascular complications [1-7]. Hypoglycemia is associated more with old oral hypoglycemic agents such as sulfonylurea, as they have longer half-lives [1, 4-8]. On the other hand in spite of proper treatment and maximum dosage of Sulfonylurea, hyperglycemia (especially post-prandial) is still a problem in diabetic patients $[1,9,10]$. Repaglinide which mainly decreases postprandial blood glucose and FBG might control

*Address correspondence to this author at the Gorgan Faculty of Medicine, Department of Biochemistry and Biophysics, Metabolic Disorders Research Center, Gorgan Faculty of Medicine, Golestan University of Medical Sciences, Gorgan, Golestan Province, Iran; Tel: +98(171)4421651;

Fax:+98(171) 4440225; E-mail:abdoljalal@yahoo.com the glycemic excursions in DM2 patients. The risk of hypoglycemia is lower with Repaglinide, because of shorter halflife as compared to Sulfonylurea [9]. Repaglinide belongs to the Meglitinide class with benzoic acid in its structure [1]. This drug decreases blood glucose level by stimulating the release of insulin and has a short half-life. The drug, introduced in 1995[4-8], is used as a second line in DM2 if the hyperglycemia is not controlled by other first line drugs. But since it has the ability to control glycemic variability via lowering post-prandial glucose, therefore, it can be recommended to be used in DM2 as the first line treatment. In the present study, it has been used as a the first line drug treatment for new onset of DM2 patients and their glycemic excursions have been monitored in order to investigate whether the drug in combination with 3 days CGMS can reduce glycemic excursions in this patients group. The first continuous glucose monitoring system that was approved by FDA was MiniMed. MiniMed is continuously in contact with patient's 
abdomen for 72 hours via a tiny glucose sensing device which is inserted just under the skin of patient's abdomen. The system automatically records an average glucose value every 5 minutes. During 72 hours 864 recordings prepare a chart showing exact monitoring of blood glucose fluctuations during a day, especially at times like midnight (the risk of hypoglycemia is more at this time). It does not provide real time glucose values to the patient wearing it. The data saved in the system during monitoring usually lasts 3 days and can only be downloaded by the physician. Patients can be informed about their glycemic excursions, food and activities that have any effect on glycemic variability (as during CGMS monitoring patients should record the food time and type and also activity like exercise in a questioner). These observations are helpful in deciding the exact dosage, diet and patient's activity to control blood glucose precisely and prevent hypoglycemic and hyperglycemic attacks [9, 15]. It is approved to be used as a holter type monitoring system which record minutes to glycemic control in DM1 patients. But few studies of applying CGMS in type 2 diabetic patients have been published. The aim of this study was to determine if CGMS could improve glycemic excursions in new onset of DM2 patients as an adjuvant to Repaglinide.

\section{MATERIALS AND METHODS}

Fifteen new DM2 patients, aged between 30-60 years old whose FBG was $\geq 126 \mathrm{mg} / \mathrm{dl}$ were selected. Patient's data such as age, height, weight, blood pressure, Body Mass Index (BMI), underlying diseases and drug history were recorded. Fasting blood glucose (2 times tests), glycated hemoglobin (HbA1C), blood glucose, 2-hour postprandial blood glucose (2hpp), urea, Creatinine, serum glutamate oxaloacetate transferase (SGOT) and serum glutamate pyruvate transferase (SGPT) were checked for all of the patients. All biochemical parameters were measured by commercial kit using spectrophotometer technique. Weight was then measured, while subjects were minimally clothed without shoes, using digital scales. Height was measured in standing position without shoes using tape meter while the shoulder was in a normal position. Body mass index (BMI) was calculated as weight in kilograms divided by height in meters squared. Systolic and diastolic blood pressure was measured twice after 10-15 minutes resting in sitting position from the right hand]. Exclusion criteria were: renal or hepatic failure, patients that used fibrats as triglyceride lowering drugs and FBG $\geq 250 \mathrm{mg} / \mathrm{d}$. At first step, we prescribed diabetic diet and exercise (30 minute walking every day) for three weeks. At the end of 3rd week the FBG and postprandial Glucose of all patients were evaluated. At this stage, 4 patients whose FBG and postprandial glucose levels were found to be in acceptable range were excluded from the study. The study continued with those patients whose FBG or postprandial glucose level was more than $120 \mathrm{mg} / \mathrm{dl}$ or $180 \mathrm{mg} / \mathrm{dl}$, respectively. Eleven patients were then asked to wear a continuous glucose monitoring system for 72 hours. The CGMS consists of a glucose oxidase sensor inserted in the subcutaneous fat of abdominal wall, and reacts with glucose in the interstitial fluid. This reaction creates electronic signals and their averages were stored in the device after every 5 minutes. During this period, patients controlled their capillary blood glucose level four times a day by a Glucometer (Accue check) and input the data into the CGMS monitor for calibration of the device. All patients were also asked to record in a questioner the time and type of all meals and the time of exercise (30 minutes walking a day). At the end of the third day, all the sensors were removed from the patients and the CGSM data was downloaded and glucose profiles were created for further analysis. The CGMS glucose profiles were then reviewed. The patients were inquired about the affects of special foods and walking on their glycemic variability, based on their CGMS profile and their records in the form of questioner on the type and time of foods and time of exercise. At this step, one of the patients decided to leave the study and the study continued with ten patients. They were prescribed Repaglinide $0.5 \mathrm{mg}$ three times before meals. Patients were also asked to keep their diet and their exercises for 1 month. At the end of first month, their FBG and postprandial BG were measured for further analysis. Once again all patients were asked to wear CGMS for 3 more days while taking Repaglinide. After a 3-day period, all the sensors were removed from the patients and the CGSM data were downloaded and glucose profiles were created for further analysis. Finally, their blood glucose fluctuations were compared to their initial blood glucose profiles prior to the treatment with Repaglinide.

Statistical analysis and reporting of obtained data were carried with the help of SPSS-16, paired student t-test and Chi-Square. P-value $<0.05$ was considered to be statistically significant.

\section{RESULTS}

In the first stage, fifteen newly diagnosed type 2 diabetic patients were enrolled. In 4 patients, after 3 weeks of diabetic diet and exercise, fasting and postprandial blood sugar was in the normal range. Thus, they were excluded from the study. One patient at the first phase of the study after completing the first time CGMS (before intervention) was not willing to continue the study. A total of ten patients (5 male and 5 female) with mean ages of $45.7 \pm 6.46$ year old, completed trial without withdrawal problems. Medical and drug histories were negative in all patients. Patient's characteristics have been summarized in Table 1. Among all patients that wore CGMS before and after intervention, only one pa-

\section{Table 1. Characteristics of Diabetic Patients}

\begin{tabular}{|c|c|}
\hline Parameters & Mean \pm SD \\
\hline \hline Age (year) & $45.7 \pm 6.46$ \\
\hline BMI $\left(\mathrm{kg} / \mathrm{m}^{2}\right)$ & $28.15 \pm 3.9$ \\
\hline Systolic Blood pressure (mmHg) & $117.5 \pm 12.7$ \\
\hline Diastolic Blood pressure (mmHg) & $78.2 \pm 7.5$ \\
\hline FBG (mg/dl) & $174.2 \pm 26.2$ \\
\hline $2 \mathrm{hpp}(\mathrm{mg} / \mathrm{dl})$ & $236.6 \pm 59.4$ \\
\hline HbA1C (\%) & $8.67 \pm 1.08$ \\
\hline Creatinine (mg/dl) & $0.85 \pm 0.1$ \\
\hline
\end{tabular}

FBG: Fasting blood glucose, BMI: Body mass index, 2hpp: 2-hour postprandial blood glucose and HbA1C: Glycated hemoglobin. 
tient $(5 \%)$ complained of inflammation at the insertion site of CGMS. This situation was controlled through antibiotic. As shown in Tables $\mathbf{2}$ and $\mathbf{3}$, there were significant differences between FBS measured by laboratory and CGMS before and after treatment $(\mathrm{P}<0.001)$. The mean total blood sugar level (recorded by Glucometer) before intervention was significantly higher than after the therapy $(230.9 \pm 67.1$ vs. $146.5 \pm 45.9 \mathrm{P}=0.02, \mathrm{t}=2.58$ ). Patients with $\mathrm{FBG} \geq 250 \mathrm{mg} / \mathrm{dl}$ were excluded. According to CGMS glucose profiles, those patients whose BG was more than $400 \mathrm{mg} / \mathrm{dl}$ in their profiles before intervention, showed the effectiveness of CGMS in detection of hyperglycemia. As shown in Table 3, reduction in FBG and 3hpp was significant after intervention. Blood sugar excursions recorded by CGMS before and after intervention were shown in Table 4 , and mean reduction of blood sugar after therapy was showed in Table 5. The mean absolute differentiation between glucometer and CGMS, before and after intervention, was $7.97 \pm 0.3$ and $10.07 \pm 3.6$ percent, respectively. A correlation was found between glucometer and CGMS. The mean glucose readings during CGMS before and after intervention were 789.1 \pm 89.63 and $855.2 \pm 134.64$, respectively. Glycemic excursions defined through the device as hypoglycemia $(<50 \mathrm{mg} / \mathrm{d})$ and hyper- glycemia $(>180 \mathrm{mg} / \mathrm{d})$ during 72 hours of CGMS before and after intervention were $7.6 \pm 5.2$ and $6 \pm 4.5(p-=0.49)$, respectively. No statistical differences were found between the number of hyperglycemic and hypoglycemic attacks (Table 4), but the duration of hyperglycemic episodes was significantly reduced after intervention $(21 \pm 26.1$ VS $57.7 \pm 35.3$ hour, $\mathrm{p}=0.001)$. Patients who experienced a mean of $0.3 \pm 0.67$ episodes of hypoglycemia after therapy, did not show any hypoglycemic episode before intervention $(\mathrm{P}=0.19)$.

\section{DISCUSSION}

In this study, we used CGMS as a monitoring system to detect glycemic excursions in new onset of DM2 patients before and after treatment with Repaglinide. The results of present study showed that CGMS could be a useful adjuvant for Repaglinide in new onset of DM2 patients. Information gathered through conversing with the patients about their glucose variability as per CGMS profiles and factors that may likely affect glycemic excursions (types of different foods, exercise) could be considered as an advantage of

Table 2. The Glycemic Control of Parameters Measured by Laboratory and Glucometer before and after Intervention

\begin{tabular}{|c|c|c|}
\hline Parameters & Baseline & After Intervention \\
\hline \hline FBG $^{*}(\mathrm{mg} / \mathrm{dl})$ & $174.2 \pm 26.2$ & $121.3 \pm 32.2$ \\
\hline 2-hour postprandial blood glucose* $(\mathrm{mg} / \mathrm{dl})$ & $232.6 \pm 59.4$ & $135 \pm 41.7$ \\
\hline Mean total BG **(mg/dl) & $230.9 \pm 67.1$ & $146.5 \pm 45.9$ \\
\hline
\end{tabular}

Fasting blood glucose (FBG*) measured by laboratory, Blood glucose $\left(\mathrm{BG}^{* *}\right)$ measured by Glucometer.

Table 3. Baseline and After Intervention of Glycemic Control Parameters Measured by CGMS

\begin{tabular}{|c|c|c|}
\hline Parameters & Baseline & After Intervention \\
\hline \hline FBG* $(\mathrm{mg} / \mathrm{dl})$ & $82.6 \pm 222.9$ & $142.9 \pm 54.31$ \\
\hline BG $^{*}$ 3 hour after breakfast (mg/dl) & $221.4 \pm 77.3$ & $141.8 \pm 43.78$ \\
\hline BG 3 hour after lunch (mg/dl) & $230.9 \pm 77.22$ & $140.1 \pm 38.23$ \\
\hline BG 3 hour after dinner (mg/dl) & $239.2 \pm 68.63$ & $151.4 \pm 52.44$ \\
\hline Minimum BG (mg/dl) & $110.8 \pm 67.83$ & $66.3 \pm 20.76$ \\
\hline Maximum BG (mg/dl) & $324.8 \pm 63.01$ & $244.7 \pm 75.37$ \\
\hline Mean total BG (mg/dl) & $209 \pm 35.31$ & 0.001 \\
\hline
\end{tabular}

(BG*): Blood Glucose

Table 4. Blood Glucose Fluctuations Recorded by CGMS Before and After Intervention

\begin{tabular}{|l|c|c|}
\hline \multicolumn{1}{|c|}{ Parameters } & Before Intervention & After Intervention \\
\hline \hline Number of blood glucose fluctuation* & $7.6 \pm 5.2$ & $6.0 \pm 4.05$ \\
\hline Number of hypoglycemic attack & 0 & $0.3 \pm 0.67$ \\
\hline Duration of hypoglycemic attack (hour) & 0 & $5.1 \pm 14.1$ \\
\hline Number of hyperglycemic attack & $7.6 \pm 5.2$ & $5.7 \pm 4.1$ \\
\hline Duration of hyperglycemic attack (hour) & $57.7 \pm 35.3$ & 0.19 \\
\hline
\end{tabular}

* Number of episodes that patients' blood glucose were out of range set by CGMS (50-180 mg/dl). 
Table 5. Mean Reduction of Blood Glucose After Intervention

\begin{tabular}{|c|c|}
\hline Parameters & Mean \pm SD \\
\hline \hline FBG* $(\mathrm{mg} / \mathrm{dl})$ & $52.9 \pm 16.4$ \\
\hline 2-hour postprandial blood glucose* $(\mathrm{mg} / \mathrm{dl})$ & $97.6 \pm 45.7$ \\
\hline FBG**(mg/dl) & $80 \pm 66.89$ \\
\hline BG 3 hour after breakfast ** $(\mathrm{mg} / \mathrm{dl})$ & $79.6 \pm 65.3$ \\
\hline BG 3 hour after lunch** $(\mathrm{mg} / \mathrm{dl})$ & $90.8 \pm 72.5$ \\
\hline BG 3 hour after dinner** $(\mathrm{mg} / \mathrm{dl})$ & $87.6 \pm 61.4$ \\
\hline
\end{tabular}

CGMS. This study showed that Repaglinide with lowest therapeutic dose and duration could be effective at lowering 2-hour postprandial blood glucose level and fasting blood glucose. The results of this study also displayed that rate of hypoglycemic events with Repaglinide were not significant. Although the glycemic excursions before and after drug administration were not statistically significant, but CGMS findings indicated low rate and duration of excursions after the administration of Repaglinide. In CGMS monitoring, when blood glucose level exceeds out of defined range, it is recorded as excursion. Lower excursions do not necessarily represent patient's good condition, but duration of each fluctuation is more valuable. Even if the BG in a patient might be over $200 \mathrm{mg} / \mathrm{dl}$ for entire 3 days CGMS records this as only one excursion. No hypoglycemic traces were found before intervention until it became evident within 72 hours after intervention. But the mean number of hypoglycemic events was 0.3 in every patient within 72 hours after intervention. The duration of hypoglycemic events after drug administration was not statistically significant and valuable than before intervention $(\mathrm{P}=0.28$ and $\mathrm{P}=0.42)$. Some other studies showed that the rate of hypoglycemia events in patients treated with Repaglinide was less than other hypoglycemic agents and placebo $[10,11]$. In our study, the rate of hyperglycemic events before and after Repaglinide administration showed no significant differences. But the mean duration of hyperglycemic events after Repaglinide was clearly less than before it $(\mathrm{P}=0.001)$. This indicates drug efficacy in decreased duration of hyperglycemia. This study also showed that the mean fasting blood glucose level after Repaglinide administration, was clearly less than before $(\mathrm{P}=$ 0.001 and $\mathrm{P}=0.04$, respectively). The mean decreases in fasting blood glucose levels after Repaglinide administration were calculated $52 \mathrm{mg} / \mathrm{dl}$ and $80 \mathrm{mg} / \mathrm{dl}$, when it was measured by the laboratory and CGMS, respectively. Some studies showed that Repaglinide efficacy was compared with placebo. The mean decrease in fasting blood glucose was $70.2 \mathrm{mg} / \mathrm{dl}$ and $61 \mathrm{mg} / \mathrm{dl}$ for Repaglinide and placebo, respectively, which was obviously greater than placebo $[12,13]$. Some other studies indicated that there was a significant decrease in fasting blood glucose level during Repaglinide treatment $[10,11,14-17]$. The mean 2 -h postprandial blood glucose level, as measured by the laboratory and CGMS, and 3 hours after meal (breakfast, lunch and dinner), was also clearly decreased after Repaglinide administration. It was considered to be in the therapeutic range of postprandial blood glucose (less than $180 \mathrm{mg} / \mathrm{dl}$ ). The mean decrease in postprandial blood glucose level, as measured by the laboratory (after Repaglinide administration compared with before it), was $97 \mathrm{mg} / \mathrm{dl}$. The mean decreases in 3 hours postprandial blood glucose level (breakfast, lunch and dinner), as measured by CGMS, were 79, 90 and $87 \mathrm{mg} / \mathrm{dl}$, respectively. This showed a clear and significant reduction as compared before the treatment. In one study, Repaglinide efficacy was compared with placebo, the mean decrease in postprandial blood glucose level was $104 \mathrm{mg} / \mathrm{dl}$ which showed a significant decrease [12]. In another study, the mean decrease in 2$\mathrm{h}$ postprandial blood glucose level was $111.6 \mathrm{mg} / \mathrm{dl}$, which was significantly compared with placebo [13]. In most previous studies, Repaglinide dose and duration were more than our study in order to achieve the targeted fasting blood glucose and postprandial [12-16]. This study suggested that CGMS might act as an adjuvant to control blood glucose level. It was found that glycemic control was better in patients who were more cooperative during and after CGMS application. Several studies have shown that application of CGMS on type 1 and 2 diabetic patients has beneficial effects in decreasing the blood glucose level. One study showed that $1.1 \%$ reduction in $\mathrm{HbA} 1 \mathrm{C}$ (after 5 weeks) was observed only by adjusting time of insulin administration [18]. Several other studies have referred significant decrease in $\mathrm{HbA} 1 \mathrm{C}$ in DM1, and few studies have been published showing the application of CGMS in DM2 [19-23]. Overall, in this study, patient cooperation in CGMS, middle age of the patients (mean age $45 \pm 6.4$ years), low baseline of hyperglycemia (mean fasting blood glucose $174 \pm 26 \mathrm{mg} / \mathrm{dl}$ and $2-\mathrm{h}$ postprandial $232 \pm 59 \mathrm{mg} / \mathrm{dl}$ ), no history of underlying disease, and no medical treatment, have actually improved Repaglinide efficacy at lowering blood glucose level. On the other hand, racial and geographical location and diet are probably effective in response to Repaglinide. Since minimum dose and the minimum time were applied for achieving therapeutic effects of the drug, Repaglinide may be used in lower doses as first therapeutic step for patients who have clinical features similar to the patients in this study. Overall, the results of this study indicate that Repaglinide is a safe and appropriate medication for decreasing blood glucose in newly diagnosed type II diabetic patients who having no underlying diseases. Moreover, it is apparent that CGMS can be used as an effective method in appropriate glycemic control and even as an effective adjuvant agent along with other medication in type 1 and 2 diabetic patients.

\section{CONFLICT OF INTEREST}

The authors confirm that this article content has no conflicts of interest.

\section{ACKNOWLEDGEMENTS}

None declared.

\section{REFERENCES}

[1] Buse, J.B.; Polonsky, K.S.; Burant, C.F. Type 2 diabetes mellitus. In: Williams Text Book Of Endocrinology; Kronenberg, H.M.; Melmed, S.; Polonsky, K.S.; Larsen, P.R. Eds.; $11^{\text {th }}$ ed; Saunders Elsevier: Philadelphia, 2008; pp. 1329-1389. 
[2] Sean, F.; Rizza, D.; Rizza, A. Classification and diagnosis of diabetes mellitus. In: Endocrinology. $5^{\text {th }}$ ed; Degroot, L.J.; Jameson, J.L.; Eds.; Elsevier Saunders: Philadelphia, 2006; pp. 1063-1073.

[3] Peter, H.; Knowler, B.C.; Knowler, W.C. Deffinition, diagnosis and classification of diabetes mellitus and glucose homostasis. In: Joslin's Diabetes Mellitus, $14^{\text {th }}$ ed.; Kahn, C.R.; Weir, G.C.; Eds.; Lippincott Williams and Wilkins: Philadelphia; 2005; pp. 331-339.

[4] Kahn, C.R. Etiology and phathogenesis of type 2 diabetes mellitus and related disorders. In: Principles and practice of endocrinology and metabolism; $3^{\text {rd }}$ ed; Becker, K.L.; Eds.; Lippincott Williams and Wilkins: Philadelphia; 2001; pp. 1315-1326.

[5] Allison, B.; Maratos - flier, G.; Maratos-flier, E. Oral agents for the treatment of type 2 diabetes mellitus. In: Principle And Practice of Endocrinology and Metabolism: $3^{\text {rd }}$ ed.; Becker, K.L.; Ed.; Lippincott Williams and Wilkins: Philadelphia; 2001; pp. 1344-1347.

[6] Lebovitz, H.E. Management of hyperglycemia with oral antihyperglycemic agents in type 2 diabetes. In: Joslin's Diabetes Mellitus; $14^{\text {th }}$ ed.; Kahn, C.R.; Weir, G.C.; Eds; Lippincott Williams and Wilkins: Philadelphia; 2005; pp. 687-710.

[7] Stephen, N.; Granner, D.; Daryl, K. Insulin, Oral hypoglycemic agents, and the pharmacology of endocrine pancreas. In: Goodman And Gilman's The Pharmacological Basis Of Therapeutics; $10^{\text {th }}$ ed.; Hardman, J.G.; Limbird, L.E.; Eds.; Mc Graw-Hill: New York; 2001; pp. 1679-1714.

[8] Buse, J.B. Management of type 2 Diabetes mellitus. In: Endocrinology; $5^{\text {th }}$ ed.; Degroot, L.G.; Jameson, J.L.; Eds.; Elsevier Saunders: Philadelphia; 2006; pp. 1231-1248.

[9] Buckingham Bruce, A.; Kollman, C.; Beck Roy, W.; Tansey, M.J.; Fox, L.A.; Weinzimer, S.A.; Ruedy, K.J.; Tamborlane, W.V. Evaluation of factors affecting CGMS calibration. Diabetes Technol. Ther., 2006, 8 (3), 318-325.

[10] Papa, G.; Fedel, V.; Rizzo, M.R.; Fioravanti, M.; Leotta, C.; Solerte, S.B.; Purrello, F.; Paolisso, G. Safety of type 2 Diabetes treatment with repaglinide compared with glibenclamide in elderly people. Diabetes Care, 2006, 29 (8), 1918-1920.

[11] Eriksson, J.G.; Brogard, J.M.; Londin - Olsson, M.; Glauson, P.; Rasmussen, M. The safety of repaglinide administered in combination with bed time NPH- insulin in patients with type 2 diabetes. A randomized, Semi- blinded, parallel - group, multicenter trial. Diabetes, 1999, 48 (suppl 1), A360.

[12] Hatorp, V.; Oliver, S.; Su, C.A. Bioavalibility of Repaglinide, a novel anti diabetic agent, administered orally in tablet or solution form or intravenously in healthy male volunteers. Int. J. Clin. Pharmacol. Ther., 1998, 36(12), 636-641.

[13] Goldberg, R.B.; Einhorn, D.; Lucas, C.P.; Rendell, M.S.; Damsbo, P.; Huana, W.C. A randomized placebo - controlled trial of repaglinide in the treatment of type 2 diabetes. Diabetes Care, 1998, 21 (11), 1897-1903.

[14] Li, J.W.; Tian, H.M.; Yu, H.L.; Zhang, X.X.; Zhao, G.Z.; Wang, J.N. Comparison of efficacy between nateglinide and repaglinide in treating type 2 diabetes: a randomized controlled double - blind clinical trial. Sichuan Da Xue Xue Bao Yi Xue Ban, 2005, 36 (2), 267-270.

[15] Abbink, E.J.; Van der wal, S.P.; Sweep, C.U.; Smits, P.; Tack, C.J. Compared to glibenclamide, repaglinide treatment results in a more rapid fall in glucose level and beta-cell secretion after glucose stimulation. Diabetes Metab. Res. Rev., 2004, 20 (6), 466-471.

[16] Landgraf, R.; Bilo, H.J.; Muller, P.G. A comparison of repaglinide and glibenclamide in the treatment of type 2 Diabetes patients previously treated with sulphonylurease. Eur. J. Clin. Pharmacol., 1999, 55 (3), 165-171.

[17] Moses, R.; Slobodniuk, R.; Boyages, S.; Colagiuri, S.; Kidson, W.; Carter, J.; Donnelly, T.; Moffitt, P.; Hopkins, H. Effect of repaglinide addition to metformin monotherapy on glycemic control in patients with type 2 diabetes. Diabetes Care, 1999, 22 (1), 119-124.

[18] Bode, B.W.; Gross, T.M.; Thornton, K.R.; Mastrototaro, J.J. Continous glucose monitoring used to adjust diabetes therapy improves glycosylated hemoglobin: a pilot study. Diabetes Res. Clin. Pract., 1999, 46 (3), 183-190.

[19] Maia, F.F.; Araujo, L.R. Efficacy of continous glucose monitoring system (CGMS) to detect post prandial hyperglycemia and unrecognized hypoglycemia in type 1 diabetic patients. Diabetes Res. Clin. Pract., 2007, 75 (1), 30-34.

[20] Salardi, S.; Gualandi, S.; Zucchini, S.; Cicognani, A.; Santoni, R.; Cacciari, E.; Ragni, L. The glucose area under the profiles obtained with continouse glucose monitoring system relationships with $\mathrm{HbA} 1 \mathrm{C}$ in pediatric type 1 diabetic patients. Diabetes Care, 2002, 25 (10), 1840-1844.

[21] Nyback- Nakell, A.; Von Heijne, M.; Adamson, U.; Lins, P.E.; Landstedt-Hallin, L. Accuracy of continous nocturnal glucose screening after 48 and 72 hours in type 2 diabetes patients on combined oral and insulin therapy. Diabetes Metab., 2004, 30 (6), 517-521.

[22] Oueslati, I.; Ben Said, R.; Kammoun, I.; Haouat, E.; Ben Salem, L.; Turki, Z.; Ben Slama, C. Continuous glucose monitoring in glimipiride plus metformin treated type 2 diabetic patients during Ramadan month. Tunis Med., 2012, 90 (10),735-739

[23] Lu, H.; Castells, S.; Hagerty, D.; Quintos, J.B.Study of glucose profile with continuous glucose monitoring in adolescents with poorly controlld type 2 diabetes mellitus. J. Pediatr. Endocrinol. Metab., 2008, 21 (8), 729-736

This is an open access article licensed under the terms of the Creative Commons Attribution Non-Commercial License (http://creativecommons.org/licenses/by-nc/3.0/) which permits unrestricted, non-commercial use, distribution and reproduction in any medium, provided the work is properly cited. 